\title{
The Timing of Research Consent
}

\section{Benjamin Sachs ${ }^{1}$}

Accepted: 6 August 2021 / Published online: 28 September 2021

(C) The Author(s) 2021

\begin{abstract}
This essay is about the timing of research consent, a process that involves (potential) participants being given information about, among other things, upcoming research interventions and then being invited to waive their claims against those interventions being undertaken. The standard practice, as regards timing, is as follows: (potential) participants are invited to waive all their claims at a single moment in time, and that point in time immediately follows the information-provision. I argue that there we're not justified in keeping to this practice. What we ought to do is disaggregate the claimwaiving part of the process and move it later, such that the (potential) participant is invited to waive her claim against the undertaking of any given intervention only the immediate moment before that intervention is to be undertaken.
\end{abstract}

Keywords Informed consent · Consent form

\section{Introduction}

In medical research, what generally goes by the name "the consent process" is a conjunction of two processes: the process by which information about the study is conveyed from researcher to prospective participant and the process by which the prospective participant waives her claims against the researcher conducting otherwise claim-violating research interventions on her. This essay is about the timing of those two processes. Standard practice is for the claimwaiving process to occur immediately after the conclusion of the information-conveying process, and for each of the two processes to be carried out in a one-shot manner. However, the last 25 years has seen a steady stream of commentators arguing that the claim-waiving process should be temporally extended instead of one-shot. ${ }^{1}$ These commentators have called for researchers to require participants, at various points over the course of their participation in the study, to "reaffirm their consent", by which they mean reaffirm their waiving of their

${ }^{1}$ See, e.g., Allmark and Mason 2006, Wendler and Rackoff 2002.

Benjamin Sachs

bas7@st-andrews.ac.uk

1 University of St. Andrews, Edgecliffe, The Scores, St. Andrews KY16 9AL, UK 
claims. I believe that these calls are on the right track, in that it's not ideal for the claimwaiving process to be a one-shot deal, but still missing something important.

I argue in $\S 2$ that the research participant should be invited to waive her claim against each research intervention only in the immediate moment before it is to be undertaken. I call this process the Disaggregated Contemporaneous Claim-Waiving Process and I argue that it can fulfil the moral and legal function of a claim-waiving process just as well as can either of the two kinds of claim-waiving processes just mentioned, in addition to possessing two virtues they don't. I intend this new claim-waiving process, and the argument for it, to apply only to complex experimental studies - studies that involve more than one intervention, where an 'intervention' is the researcher doing something to the participant or the participant doing something to herself at the researcher's request.

$\S 3$ turns away from questions about the moral and legal functions of a claim-waiving process and toward issues concerning its effect on the psychology of the participant. There I argue that the Disaggregated Contemporaneous Claim-Waiving Process, if properly carried out, will do no worse than do the above-mentioned alternatives at focusing the participant's mind on the key information about the study, helping her to settle from the start an intention as to whether to participate through to completion, and, as the study goes on, freeing her from any feeling of being pressured into continuing to participate. I argue, further, that the process can be expected to be motivationally inert and that this is a good thing.

As to the one-shot claim-waiving process and the temporally extended claim-waiving process, by the end of the essay I will have shown that each of them both overshoot and undershoot the mark. They overshoot the mark by giving the researcher greater legal protection, at least potentially and in some cases, than we should want her to have, and - at least if my empirical speculation in $\S 3$ is accurate - by leaving the participant, at least potentially, with a stronger moral motivation than we should want her to have. They undershoot the mark in virtue of eliciting claim-waiving that is likely to be underinformed. I summarize these points in $\S 4$, the conclusion.

I make my arguments in this essay from the perspective of public policy. I am asking what practices we should put in place, such that if researchers follow them in their dealings with participants, then our legitimate interests will be well served. Consequently, in what follows I will often ask "What should we want?" questions, where the "we" denotes the members of the public, who have legitimate interests in the behaviour of researchers and participants because we fund medical research through our taxes, stand to gain from the fruits of its successes, and constitute the pool of potential research participants. (Since the consideration regarding taxes applies only to publicly funded studies, my arguments here apply only to such studies.)

\section{The Moral and Legal Functions of Claim-Waiving}

\subsection{An Argument for Contemporaneity}

The question of timing that divides adherents of the One-Shot Claim-Waiving Process (OSCP) and the Temporally Extended Claim-Waiving Process (TECP) is as follows: If a researcher is to subject a participant to an experimental intervention and doing so would normally violate a claim that the participant has against the researcher, at what point(s) in time should we want the participant to waive that claim? 
The longer the researcher waits, before the performing of the intervention, to ask for the participant to waive her claim against it the more timely that claim-waiving will be if provided, in the sense of being done in the light of the most up-to-date information about her circumstances and her latest thinking about whether the prudential cost-benefit profile of going through with it is satisfactory and whether going through with it is in accordance with her other, non-self-oriented, values. ${ }^{2}$ This leads to the conclusion that, for any intervention, the participant should be invited, contemporaneously with the performing of that intervention, to waive her claim against its being carried out.

\subsection{Two Virtues of Contemporaneity}

Any claim-waiving process that is contemporaneous in this way will have the following two virtues as compared to the OSCP and TECP:

1) The one already mentioned: it will involve finding out something about the participant's mental state at the very moment when it's most critical, morally speaking, what the participant's mental state is. Under the OSCP and the TECP, the participant waives all her relevant claims in a single moment before (and sometimes well before) undergoing the first intervention, and therefore for almost any given research intervention she eventually undergoes it will not be true that it occurs immediately after she waives her claim against its being carried out. This is one reason why the OSCP and TECP tend to elicit claimwaiving that is underinformed. Of course, in the case of the TECP the participant is invited to change her mind after initially waiving her claims, but nevertheless her initial claim-waiving has a moral effect: it replaces the moral default whereby the later carryingsout of each of the interventions violates claims of hers with a default in which they don't.

2) The OSCP and TECP each have the flaw of merging the two parts of consent: the information-conveying process and the claim-waiving process. They do this in virtue of treating, as the token of the participant's claim-waiving, her signing the very document that serves as the centrepiece of the information-conveying process: the consent form. My contemporaneous claim-waiving process is constructed in light of a commitment to the idea that these two processes should be kept separate to the extent possible. The reason to keep these processes separate is to ensure that the information-conveying process doesn't get overshadowed or minimized in importance, thus avoiding a documented problem (Armstrong et al. 2012) and helping to focus the participant's mind on the information provided whenever it is provided. The way we can do this is by building into the contemporaneous claim-waiving process the further principle that participants should be asked to token their claim-waiving in some way other than by signing the very document that serves the information provision function. (In $\$ 2.3$ I'll suggest an alternative way of tokening.) By cleanly isolating the conveying of information from the waiving of claims we thereby enhance the transparency of both processes. ${ }^{3}$ The OSCP and TECP each fail to do this, and their resulting tendency to draw the participant's attention away from the

\footnotetext{
${ }^{2}$ Dickert, et al. (2017), argue that protecting the participant's well-being and enabling her to act in accordance with her values are two of the functions of the medical research consent process.

${ }^{3}$ Dickert, et al. (2017), argue that creating this transparency is another one of the functions of the consent process.
} 
information provided is the second reason that the claim-waiving they elicit in any given case is likely to be underinformed.

Having identified these two virtues of a contemporaneous claim-waiving process, we can now see that any given instance of the OSCP and TECP is likely to undershoot the moral mark in two ways: 1) being carried out before all the relevant information becomes knowable, and 2) not being carried out in light of a wholehearted engagement with the information that is knowable at the time it's carried out.

\subsection{The Onerousness Objection}

Thus far in $\S 2$ I have been pointing out the advantages of adopting a contemporaneous consent process. What I have yet to concede, but of course must concede, is that any contemporaneous claim-waiving process must be disaggregated as well: since the various interventions take place at distinct moments in time, the participant's waiving of her claim against each intervention will have to be carried out individually. This leads to an obvious worry about onerousness: it seems to entail that the researcher is obligated to seek a written claim waiver from the participant separately for each intervention. Provided, however, that there are alternative ways for a participant to waive her claims, this worry is disarmed. ${ }^{4}$

Fortunately, the postulate that claims can be waived without the use of words, written or spoken, is a matter of consensus in the literature on consent. This consensus spans the divide between the two main kinds of consent theorist: those who believe that having a mental state is sufficient for waiving a claim and those who believe that performing/attempting some communicative act is necessary. Mental state theorists are friendly to the idea that claims can be waived nonverbally (Westen 2016: 274, Hurd 1999: 115, Husak 2010: 240-2). And I'm not aware of a single communicative act theorist who denies that a bodily movement can constitute a claim waiver; indeed many of them explicitly affirm it (Dougherty 2015: 230, Saunders 2012: 70-1, Carr 1990, Millum and Bromwich 2018: 49n) and some add that the absence of a bodily movement, can, likewise, constitute the waiving of a claim (Kleinig 2010: 11, Saunders 2012: 70-1, Upton 2012, Wilkinson 2012: 74, den Hartogh 2011: 303). Furthermore, I am not the first to propose that certain bodily movements on the part of research participants be treated as nonverbal claim-waiving; Mueller and Instone (2008: 388) propose the same. Finally, it's worth mentioning that nonverbal claim-waiving is the

\footnotetext{
${ }^{4}$ A connected, but related, worry is that in advance of each intervention the researcher will need to provide the participant with information about the risks and benefits of that intervention. In $\$ 2.2$ I advocated keeping the information-conveying process separate from the claim-waiving process, but I prescinded from the question of the timing of the information-conveying. Clearly, though, it would be a problem for me if there were something important to be gained, morally speaking, from disaggregating the information-conveying process, as that process would thereby become enormously cumbersome and disruptive. Fortunately, I doubt that there is anything morally important to be gained from such disaggregation. One might, of course, think that for any piece of information relevant to a participant's decision whether to undergo some intervention, $\varphi$, it is morally important that the participant understand that information at the moment when she waives her claim against $\varphi$; this if true would speak in favour of having the information-conveying process, for any given intervention, happen immediately before the claim-waiving process for that intervention, which would require that the information-conveying process as a whole be disaggregated. But it is hardly open to a defender of the OSCP and TECP to make a big deal out of the issue of understanding, as there is a wealth of research demonstrating that under current consent processes participants understand quite poorly what they are waiving claims against when they sign a consent form. In any event, Bromwich and Millum (Bromwich and Millum 2015, Millum and Bromwich 2018) have made a strong case that understanding is not morally important in this way.
} 
default mode of claim-waiving in clinical practice. The following are examples of how nonverbal claim-waiving commonly works in clinical practice and could work in research settings:

- The physician/researcher says to Jones, "May I swab the inside of your cheek?". Jones opens her mouth as the researcher picks up the swab and leaves it open until the researcher has removed the swab from her mouth.

- The physician/researcher, holding an otoscope, says to Jones, "May I shine this light into your ear so as to get a look at your ear drum?". Jones sits still while the researcher goes ahead with the examination.

- The physician/researcher says to Jones, “May I take a blood sample from you?". Jones rolls up her sleeve and extends her arm, palm up.

I take myself to have shown that there is nothing radical about the suggestion, either from the perspective of theory (specifically, the theory of consent) or from the perspective of (medical) practice, that certain actions or inactions on the participant's part be treated as constituting the waiving of a claim against a certain research intervention being carried out on her. And while I will not insist, as part of the new research claim-waiving process that I am proposing, that researchers never require participants to engage in verbal claim-waiving, I do want to build into it the stipulation that nonverbal claim-waiving be taken as the default. Otherwise, this new process would indeed be very onerous.

Having fended off the onerousness objection, I can now embrace the disaggregation that necessarily comes along with contemporaneity. ${ }^{5}$ For that reason I label the claim-waiving process for which I'm arguing in this essay the Disaggregated Contemporaneous ClaimWaiving Process (DCCP).

\subsection{Two Legal Inefficacy Objections}

My response to the onerousness objection leads naturally to two additional objections. Defaulting to nonverbal claim-waiving means defaulting away from the use of signed consent forms, and one might think that signed consent forms secure some desirable legal upshot that the use of a nonverbal claim-waiving process doesn't.

\subsubsection{A Signed Consent Form as Legal Protection for the Participant}

One proposal is that a consent form signed by the researcher provides legal protection for the participant. The idea would be that if the researcher performs an intervention on the participant that wasn't mentioned in the signed consent form, the participant could use the signed consent form as evidence in a civil proceeding for battery.

The way in which a consent form signed by the researcher would work to the participant's legal advantage is by constituting evidence as to what information the researcher conveyed to

\footnotetext{
${ }^{5}$ Given my embrace of disaggregation, it is incumbent upon me to say how finely we ought to individuate interventions. However, I don't have a simple all-purpose answer to the question of how finely to individuate interventions. Fortunately, however, there is an easy rule of thumb available: individuate interventions as finely as it is possible to without consigning the researcher and participant to labour against impossible-to-meet, dangerous-to-meet, or pointless-to-meetclaim-waiving requirements. The reason why defaulting to finegrainedness should be unproblematic is that the claim-waiving process I'm proposing can be satisfied quickly, easily and seamlessly in most cases by the researcher's accepting a nonverbal token of consent.
} 
the participant. However, in this essay I am making claims only about how the claim-waiving process should go. The only thing I am saying about the information-conveying process is that it should be kept separate from the claim-waiving process. If it's important, for the legal protection of the participant, that the document that the researcher provides to the participant by way of conveying information also contains the researcher's signature, that's fine by me. I am insisting only that that document not be thought of, nor treated, as part of the claim-waiving process.

\subsubsection{A Signed Consent Form as Legal Protection for the Researcher}

The other proposal would be that a consent form signed by the participant provides legal protection for the researcher by rendering it more difficult for her to be found guilty of the crime of battery or liable for the tort of battery. ${ }^{6}$

To make this proposal more specific, a question needs to be answered: How does a participant's signature on a piece of paper need to be conventionally understood and treated in order for it to provide legal protection to the researcher? There are exactly two candidate answers to this question. 1) It needs to be conventionally understood and treated as an avowal of understanding. 2) It needs to be conventionally understood and treated as a token of claimwaiving. If the objection relies on the first answer, then it causes no trouble for my project here. Such an objection, if valid, would have implications only for how the informationconveying process should be structured, whereas I am discussing how the claim-waiving process should be structured.

If the objection relies on the second answer, then I do need to respond to it, and my response comes in two parts. First, if in the course of litigation the question arises whether the participant really did waive her claim against a certain intervention, the burden of proof will always rest with the prosecution/claimant. This means that the researcher will already begin battery proceedings from a position of advantage. Should we want the researcher to start from an even more advantaged position? It's not obvious that we should. ${ }^{7}$

Second, if we should - or, more likely, if there are certain rare cases in which we should, such as in the case of a very high-risk research intervention, because without the added legal protection most researchers wouldn't dare to carry out the intervention- then we can act on that from within the confines of the DCCP by allowing the researcher to demand that the participant token her claim-waiving in written form. ${ }^{8}$ My brief here is not against written claim-waiving; it is against claim-waiving that is not contemporaneous and disaggregated.

\subsection{Summary}

I have argued in $\$ 2$ that the DCCP can fulfil the moral function of a claim-waiving process, and I have shown as well that it can fulfil the important legal functions as well. In addition, I've argued that it has two virtues that the OSCP and TECP lack. Finally, I've demonstrated that it can escape the onerousness objection.

\footnotetext{
${ }^{6}$ I thank Gerard Porter for pointing out this possibility to me.

7 Thanks to Hallie Liberto for pointing this out to me.

${ }^{8}$ So long as the document the participant is asked to sign isn't the same document used to carry out the information-conveying function.
} 
In the next section I examine what effect going through the DCCP is likely to have on the psychology of the participant, and I ask whether any of these effects count as benefits or drawbacks of the DCCP as compared to the OSCP and TECP.

\section{Concerns about the DCCP's Effects on the Psychology of the Participant}

\subsection{Two Initial Worries}

One worry about the DCCP targets its disaggregation aspect specifically. ${ }^{9}$ Whatever might be said against inviting prospective participants to waive at a single moment in time the various claims they have against the entire set of interventions constitutive of their participation in the study, one can at least conjecture that the high stakes nature of that moment serves to focus the prospective participant's mind on the risks and benefits of proceeding. By contrast, with a disaggregated claim-waiving process there is no high-stakes moment (except in those studies that contain particular interventions that are very high stakes on their own).

However, this objection is undermined by a key fact that I have not yet brought into the discussion: the fact that nearly every consent form that is used in complex experimental studies contains, and is indeed required to contain, a boilerplate clause declaring something like, "You are free to withdraw from the study at any time". I take these clauses to be conveying in everyday language the proposition that the claim-waiving that the participant tokens by signing the consent form is revocable; i.e., that the claim can be reinstated by the participant at will. And, indeed, researchers act accordingly: they would never force an intervention on a participant who says that she no longer wants to go through with it, even if that participant earlier signed a consent form and in so doing tokened her waiving of her claim against that intervention being carried out on her.

Given this, under the OSCP and the TECP the participant faces a new decision, in advance of each intervention, whether to reinstate the claim they previously possessed against that particular intervention being carried out. In a very real sense, then, the OSCP and TECP are themselves disaggregated. This objection, then, cannot be used to demonstrate that the DCCP has a flaw not possessed by its alternatives.

Another concern targets the DCCP's contemporaneity aspect. ${ }^{10}$ One might worry about the quality of contemporaneous claim-waiving, given the pressurised nature of making a decision, in the immediate moments in advance of a planned intervention, about whether to go through with it. A conscientious participant considering whether to waive her claim against some imminent intervention might anticipate feeling guilty over refusing to so waive, at least in those cases in which the researcher has expended time, effort and resources in getting ready to perform her part of the intervention. Again, however, the OSCP and TECP do not come off looking better than does the DCCP in this regard. Just as the OSCP and TECP are covertly disaggregated, they are also covertly contemporaneous. Both of those processes give the participant the moral power to reinstate her claim against each intervention-a power she can exercise at any moment up to and including the moment immediately preceding each intervention. If we should worry that the decision whether to waive one's claim will be too

\footnotetext{
${ }^{9}$ I thank Lara Jost and Eline Gerritsen for alerting me to this possible objection.

${ }^{10}$ I thank Adam Etinson and Jakob Hinze for alerting me to this objection.
} 
pressurised when the moment of opportunity is contemporaneous with the carrying out of the procedure that the claim is against then we should also worry that the decision whether to reinstate one's claim will be too pressurised when the moment of opportunity is contemporaneous in the same way. ${ }^{11}$

\subsection{A Generalizable Lesson}

In light of these last two objections and my responses to them, a broader argument in favour of the DCCP emerges. Because the participant's claim-waiving, given the OSCP, is revocable, and because the participant's initial claim-waiving, given the TECP, is revocable as well, under both of these processes participants face the decision, separately with respect to each intervention, whether to reinstate their claim against that intervention in the moments immediately preceding its being carried out. Consequently, there is a sense in which the DCCP simply brings out into the open and makes official a moral mechanism that the OSCP and TECP possess covertly. However, by opting in favour of the DCCP we reduce the likelihood of confusion on the participants' part (i.e., by making it so that it is only in the immediate moments preceding any intervention that they are able to exercise their moral power with respect to that intervention) and focus the researcher's attention where it ought to be focused (i.e., on assessing, in the immediate moment preceding each intervention, whether the participant is waiving her claim against it). ${ }^{12}$

\subsection{The Matter of Moral Motivation}

In $\S 3$ thus far we have been focusing on elements of the research participant's psychology that are relevant to the quality, and thus possibly the moral efficacy, of her attempts to waive her claims. I now want to turn our attention to a different aspect of the participant's psychology: her moral motivation. I want to admit straight off that I am about to make claims about the human mind without providing evidence to back them up. I think that they resonate with a reasonable armchair psychology, but still, if they're not true then the argument that this subsection makes in favour of the DCCP as against the OSCP and TECP must be set aside. In that case, however, I can fall back on my $\S 2$ arguments to the same effect.

I begin with this simple question: Should we want the typical participant to be morally motivated to see her participation through to completion? As members of the public, we

\footnotetext{
${ }^{11}$ One might wonder whether the fact that the OSCP and TECP are covertly contemporaneous undermines the first point I made against them in $\$ 2.2$, namely that the claim-waiving they elicit, in virtue of being elicited often a long time before the carrying out of the intervention against which the claim is being waived, is generally going to be underinformed. If the earlier claim-waiving is unimportant, because a later reinstating of that claim is always possible, then surely the underinformedness of it is unimportant as well. However, as I mentioned in $\S 2.1$, the earlier claim-waiving is not unimportant, as it changes the moral default.

${ }^{12}$ Of course, in emphasising the sense in which the OSCP and TECP are disaggregated and contemporaneous, like the DCCP, I naturally invite curiosity about the prospect of adopting a claim-waiving process that genuinely lacks those two features - that is, a process that involves the potential participant being invited to irrevocably waive her claims, at a single moment in time, against the entire set of interventions she is being asked to undergo. This is not the place to compare the overall merits of that possible claim-waiving process as against the OSCP, TECP, and DCCP. However, suffice it to say that such a process would face a particularly troubling version of the underinformedness objection faced by the OSCP and TECP, because under such a process a participant who has already waived her claim against an intervention would be deprived of the opportunity to reinstate the claim in light of further deliberation or changes in her circumstances that might occur between the moment of claimwaiving and the moment of the intervention.
} 
certainly have a stake in the participant completing her participation, because, as mentioned in $\S 1$, we have a stake in the success of the enterprise of medical research. This stake grows as ever more resources are sunk into her participation. I don't mean to suggest, of course, that moral considerations are the only ones that can motivate participants to see their participation through to completion. Still, though, it's not implausible to suppose that there will be occasions when all other possible sources of motivation fail to do the job on their own. So, yes, we have a stake in the typical participant's being morally motivated to see her participation through to completion, a stake that is minimal at the outset of her participation and grows steadily towards full strength as she progresses through the various research interventions.

Importantly, the very facts that make it rational for us to care about the participant's seeing her participation through to completion also ground a conditional moral obligation on her part to complete. If a participant squanders society's medical resources and thus risks delaying the introduction of new interventions and diagnostics that can augment the quality and length of people's lives, and does so for some trivial reason, she surely thereby violates a moral requirement incumbent on her. ${ }^{13}$ Consequently, the motivation that (as pointed out above) we should want her to have is motivation she will have if she's fully informed and conscientious. A fully informed and conscientious participant's moral motivation will be minimal at the outset and gradually grow, becoming quite strong as the final research intervention approaches.

An important feature of this moral obligation is that it floats free of the claim-waiving process; the fact that the participant has waived her claims does not help to ground the obligation. (Indeed, it's a confusion to think that A's waiving her claim against B could have any effect on the moral landscape other than A no longer having that claim against B.) Consequently, the corresponding motivation will float free of the claim-waiving process as well.

Given that the moral motivation we have been discussing has nothing to do with the claimwaiving process, it is worth asking whether the claim-waiving process is itself likely to engender moral motivation on the participant's part.

The answer, I think, is yes, if that claim-waiving process involves the participant signing a consent form. To see why, notice that usually signing one's name to a document constitutes the making of a promissory commitment to and thus the incurring of an obligation directed to the person or group who has drawn up and presented one with the document; we do this when we sign, for instance, mortgage agreements, rental agreements for goods of various sorts, and employment contracts. Furthermore, whether signing a document does, in any given case, result in the incurring of such a directed obligation is purely a matter of convention. There is no magic language that needs to appear in the document. Granted, some documents make an explicit statement of their own moral upshot; however, many don't (they traffic, instead, in purely descriptive language of "I will $\varphi$ ", "I undertake not to $\psi$ ", etc) and yet the signing of them has a moral upshot nonetheless.

Consequently, my conjecture is that despite the fact that the consent forms in use under the OSCP and TECP don't mention anything about the participant undertaking a commitment or an obligation, the signing of the consent form will, for many participants, have a familiar feel - a feel that is reminiscent to them of how they have felt when signing other forms (e.g., mortgage agreements, rental agreements, employment contracts) and will therefore put them in

\footnotetext{
${ }^{13} \mathrm{I}$ 'm not the first to suggest that under some circumstances it can be an obligation-violation for a participant to fail to complete her participation; see Schaefer and Wertheimer (2010: 346).
} 
something of a deontological frame of mind with respect to completing their participation in the study. This is not to say that they will entertain and endorse the proposition that they are now obligated to the researcher to see their participation through to completion, but rather that they will feel obligated or committed to doing so. This feeling is likely to lead to, or perhaps constitute, motivation to do so.

Notice, further, that in any case in which this moral motivation comes into existence it will spring into existence at full force at the moment the participant signs the consent form, because the signing of the consent form will be the sole basis of the feeling and thus of the motivation. Seen in this light, from a public policy point of view the consent form is a blunt moral instrument, since at the moment of consent form signing our stake in the participant's continued participation is precisely zero. ${ }^{14}$ Not only, then, is this moral motivation excessive (since, as we saw earlier, an informed and conscientious participant will be morally motivated, on independent grounds, to see her participation through to completion), it's also badly timed. $^{15}$

One might object that there's no such thing as excessive moral motivation on the participants' part; the more motivated they are to see their participation through to completion, the better, from a public policy perspective. This, however, is not true. If a participant continues to participate in a study at considerable cost to herself and possibly others, that is not a good outcome from a public policy perspective. An overly morally motivated participant might, for instance, choose to see her participation through to completion at the cost of passing up the opportunity to say goodbye in person to her dying mother. ${ }^{16}$

In this sub-section I've made a supplemental argument in favour of the DCCP and against the OSCP and TECP. The three central premises in this argument are 1) that an informed and conscientious participant will be morally motivated to see her participation through to completion, 2) that this motivation will be founded in her acknowledgment of an obligation incumbent upon her - an obligation having nothing to do with her having waived her claims, and 3) that that this is all we should want in terms of participant moral motivation. So, it is a good thing that the DCCP is unlikely to engender any moral motivation of its own, and a mark against the OSCP and TECP that those claim-waiving process are, by contrast, likely to give rise to further moral motivation on the participant's part. The OSCP and the TECP, in this respect, overshoot the moral mark.

Of course, whether real-world participants will actually acknowledge the obligation that the second claim above posits that they will acknowledge depends on their being given the relevant information. Consequently, during the information-provision process researchers

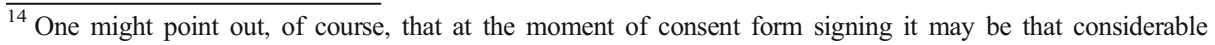
resources have already been put into the potential participant, in determining her eligibility and talking through the form with her. This does undermine, somewhat, the claim I've just made in the main text. However, it doesn't support at all the idea that we should want the participant's motivation-to-complete to burst into existence at full strength at the moment of consent form signing. What it supports is the idea that we should want the participant to begin to feel motivated to continue from the moment she begins exploring, with the research team, the possibility of participating in the study. How, if at all, we could or should act on this want is a subject for another essay.

${ }^{15}$ Furthermore, if what we did want was for the participant to incur, at the time of enrolling on the study, a fullforce obligation to see her participation through to completion, there would be better ways to achieve that end. Surely we would also want participants to know that they're undertaking such an obligation, which suggests that we should find the most transparent way possible for them to undertake it. And surely transparency would be enhanced were we to invite them, in advance of their beginning their participation, to sign what would be called a 'contract' - a sheet of paper containing no information other than a statement as to what the participant 'commits' to doing by signing that very sheet of paper.

${ }^{16} \mathrm{I}$ am assuming that one appropriate goal of public policy is the promotion of everyone's well-being.
} 
should feel free to, and indeed should, help the participant to understand the facts that ground the obligation: e.g., the potential benefits of the research, the resources being devoted to her participation and the consequences of those resources being squandered, etc.

\subsection{Intention-Settling}

I said in the previous sub-section that the act of signing a consent form is likely to cause the participant to feel committed to see her participation through to completion, and I pointed out a reason why we should be wary of inviting this causal process to unfold. In fairness, though, participant commitment is in some respects to be welcomed. A commitment, in the psychological sense, is just a strong kind of intention, and medical studies on human participants would be nearly impossible without participants adopting the intention to see their participation through to completion. A world in which participants never form this intention serves no one's interests. It is one thing for a participant to be forced out of a study before completing all the experimental interventions - say, because of a change in her circumstances or because some she has suffered a serious side effect from an early experimental intervention - quite another for her to quit because she never had an intention to complete and the next intervention she is scheduled to undergo strikes her as unappealing. A participant who is just going to quit halfway through should save herself the trouble and the risk of going through the screening process and the first batch of interventions. A world in which quitting was the norm would involve a lot of waste of research funding, and researchers would face a monumental challenge trying to pin down which individuals they could and could not count as being in the research cohort.

So there is quite a lot to be gained from the fact that the OSCP and TECP are likely to engender in participants a feeling of being committed to see their participation through to completion. However, this is an ill-gotten gain and consequently it doesn't count morally speaking. It is an ill-gotten gain because it is based on participants misunderstanding the moral contours of the situation they are in-i.e., their feeling that by signing the consent form they're undertaking an obligation or at least a commitment.

This, naturally, raises the question of whether we can have the benefits of settled intentions without the moral costs of misunderstanding. I admit that the DCCP cannot deliver the benefits, since that process doesn't encourage participants to think in a future-oriented way about their participation and thus potentially adopt an intention to see their participation through to completion. The DCCP focuses the participant's attention on the intervention she is about to undergo (should she waive her claim against it), nothing more.

I maintain that instead of relying on the claim-waiving process to engender this intentionadoption, we should rely on the information-conveying process to accomplish this: we ought to structure it in such a way as to reliably induce participants to think about whether they want to complete all aspects of their participation and, if they do, to adopt an intention to do so. Structuring it this way means the researcher encouraging the participant to pursue this line of thought and discussing with them the drawbacks, for all interested parties, of incomplete participation. This dovetails with the conclusion I reached at the end of $\S 3.3$.

\section{Conclusion}

It's a feature of life in economically advanced, western states with developed legal systems that an individual's entry into the most momentous and consequential endeavours of her life (her 
job, her marriage, her purchase of a home, her division of her estate, e.g.) is typically punctuated by the placing of her signature on a document (her employment contract, her marriage contract, her mortgage agreement, her will). The thought that a signature is necessary to make the whole ordeal official or kosher in whatever sense is most salient in the circumstances - e.g., in law or in morality - is so apparently common-sensical as to escape notice. However, one thing of which we do seem to be certain, at least if our behaviour is any indication, is that a document-signing process is a mark of, and a properly solemn response to, the gravity of the endeavour being entered in to.

With respect to complex experimental medical studies, it is the very fact about them that makes them grave-i.e., that they involve participants being subject to different sets of risks at different points in time by different interventions - that also makes them ill-suited to a process in which participants are invited to waive their claims against the entire range of interventions by signing a consent form. By embracing this process, the OSCP and TECP both undershoot and overshoot the moral and legal mark. They undershoot the moral mark by inviting participants to waive their claims in advance of all relevant information coming to light and in the absence of full engagement with the information that is available to them at the time of waiving, and they overshoot the mark by tending to leave the participant with a feeling of obligation or commitment that there's no good reason for us to want her to have, and giving researchers, at least possibly and some of the time, greater legal protection than we should want them to have.

In light of these flaws, this essay has advocated, among other things, moving away from treating the participant's signing of a document as the default way for claims to be waived in the medical research context, especially if that document is also supposed to serve an information-provision function.

We should, however, make this move slowly and carefully; this is because there is a cynical, opportunistic way of understanding the claim-waiving process that I have advocated installing as a replacement. One can choose to see that process, the DCCP, as basically nothing other than the absence of the central element of the OSCP and TECP: the signing of the consent form by the participant. Whether the DCCP actually amounts in practice to anything substantive - anything that merits the moniker 'claim-waiving process' and serves the corresponding moral purpose effectively - depends on whether members of the research community successfully adopt new practices. Researchers will have to get in the habit of looking for signs of (non-verbal)claim-waiving in the immediate moments preceding their carrying out of research interventions and will have to be trained on how to spot it. And to reap the full benefits of the new process, researchers will have to redouble their efforts to communicate effectively during the information-conveyingprocess - a process that will no longer be overshadowed by the looming payoff of the participant putting pen to paper. They will have to learn how to speak clearly, but also in a non-coercive way, to potential research participants as to what is at stake in their completing their participation once they've started it.

The practices just mentioned resist detailed codification. Unlike the TECP and (especially) the OSCP, if we tried to write up the DCCP in a law or a guidance document we would find ourselves unable to describe it in anything more than broad strokes. This new claim-waiving process requires virtue, not (so much) rule following. Researchers will have to develop and practice new skills and correspondingly rely less on their ability to follow a formula. We should not discard the status quo claim-waiving process until these new skills have been inculcated. 
Finally, before closing, it is worth inquiring as to whether the claims I've made here, concerning the timing of research consent, carry any important implications for consent more generally. I think they do. The enterprise of medical research on human subjects is an institution: a human-invented practice with defined roles, the occupants of which can change. I've argued elsewhere for the already popular view that when we create institutional roles, we thereby gain a measure of control over the moral landscape in which the occupants of those roles find themselves, by attaching specialised moral constraints as well as specialised moral licenses to the exercise of the agency that those roles make possible. ${ }^{17}$ This is what made it possible for me to approach the issue of research consent from the perspective of public policy, asking prescriptive questions about what moral situation we should want research participants to be in. If medical research on human subjects wasn't an institutional practice, the only moral questions that we could ask about it would be descriptive ones: questions about what moral situation research participants are in fact in.

Consequently, any time we fail to notice, while undertaking a moral inquiry, that the thing about which we're inquiring is an institution, we miss out on an opportunity. Oftentimes, the opportunity missed will be the opportunity to craft a more impersonal moral landscape. From the perspective of the public - the set of individuals who uphold the institution - typically the salient interest will simply be that the role-bearers within that institution behave in certain ways. ${ }^{18}$ If imposing moral obligations on the role-bearers can help that goal be achieved more reliably, that's all to the good.

Importantly, though, it's hard to see why we would ever have an interest in those obligations being directed - that is, being obligations that one person has to another. The only things we add to the moral landscape when superimposing directed obligations over their nondirected counterparts are the trappings of what Stephen Darwall (2006) calls second-personal morality: claims, accountability, and the possibility of justified reactive attitudes (guilt, resentment, regret, etc.) when those who are accountable are indeed held to account for infringing others' claims. In most public policy domains, very little of this is likely to be useful, and indeed it might even be a distraction.

Returning once more to medical research, we can certainly understand why the researcher might want the participant to make a promise, or at least feel as though she's made a promise, to the researcher to see her participation through to completion: it puts the researcher in a position, first, to demand that participants who drop out early or are considering doing so account for their decision, and, second, to feel justified resentment when these accounts are inadequate or not forthcoming. Seen in this light, it wouldn't be surprising if researchers wanted to cling to the practice that engenders such (feelings of) promissory obligation, namely the signing of the consent form. But we should keep in mind how trivial this desire is in the context of what the practice of medical research on human participants is for and what we stand to gain or lose depending on how it proceeds.

Acknowledgements I presented an earlier version of this paper to my departmental colleagues and also to an audience at the Mason Institute at the University of Edinburgh, and I wish to thank both audiences. For helpful conversations I'm grateful to Gerard Porter, Ben Schwan, Joe Millum and Emily Postan. Further, I owe a debt to Ben Schwan, Danielle Bromwich, Joe Bowen and Joe Millum for reading and commenting on a previous draft of this essay. Finally, for doing all of these things and for being a constant source of ideas and feedback for this essay, I want to single out Hallie Liberto, whose contribution was so significant as to nearly amount to coauthorship.

\footnotetext{
${ }^{17}$ Sachs 2021, Ch. 2.

${ }^{18}$ E.g., in the case of medical research on human subjects, that the participants and researchers behave so as to enable the studies undertaken be completed in a timely, cost-efficient manner, yielding valid results and inflicting as little harm as possible on participants.
} 
Open Access This article is licensed under a Creative Commons Attribution 4.0 International License, which permits use, sharing, adaptation, distribution and reproduction in any medium or format, as long as you give appropriate credit to the original author(s) and the source, provide a link to the Creative Commons licence, and indicate if changes were made. The images or other third party material in this article are included in the article's Creative Commons licence, unless indicated otherwise in a credit line to the material. If material is not included in the article's Creative Commons licence and your intended use is not permitted by statutory regulation or exceeds the permitted use, you will need to obtain permission directly from the copyright holder. To view a copy of this licence, visit http://creativecommons.org/licenses/by/4.0/.

Open Access This article is licensed under a Creative Commons Attribution 4.0 International License, which permits use, sharing, adaptation, distribution and reproduction in any medium or format, as long as you give appropriate credit to the original author(s) and the source, provide a link to the Creative Commons licence, and indicate if changes were made. The images or other third party material in this article are included in the article's Creative Commons licence, unless indicated otherwise in a credit line to the material. If material is not included in the article's Creative Commons licence and your intended use is not permitted by statutory regulation or exceeds the permitted use, you will need to obtain permission directly from the copyright holder. To view a copy of this licence, visit http://creativecommons.org/licenses/by/4.0/.

\section{References}

Allmark P, Mason S (2006) Improving the quality of consent to randomised controlled trials by using continuous consent and clinician training in the consent process. J Med Ethics 32:439-443

Armstrong N, Dixon-Woods M, Thomas A, Rusk G, Tarrant C (2012) Do informed consent documents for Cancer trials do what they should? A study of manifest and latent functions. Sociol Health Illness 34:12301245

Bromwich D, Millum J (2015) Disclosure and consent to medical research participation. J Moral Philos 12:195219

Carr CL (1990) Tacit consent. Public Aff Q 4:335-345

den Hartogh G (2011) Can consent be presumed? J Appl Philos 28:295-307

Darwall S (2006) The second-person standpoint: morality, respect, and accountability. Harvard University Press, Cambridge

Dickert NW, Eyal N, Goldkind SF, Grady C, Joffe S, Lo B, Miller FG, Pentz RD, Silbergleit R, Weinfurt KP, Wendler D, Kim SYH (2017) Reframing consent for clinical research. Am J Bioeth 17:3-11

Dougherty T (2015)Yes means yes: consent as communication. Philos Public Aff 43:224-253

Hurd HM (1999) Moral Combat. Cambridge University Press, Cambridge

Husak D (2010) The philosophy of criminal law: selected essays. Oxford University Press, New York

Kleinig J (2010) The nature of consent. In: Miller FG, Wertheimer A (eds) The ethics of consent: theory and practice. Oxford University Press, New York, pp 3-24

Millum J, Bromwich D (2018) Understanding, communication, and consent. Ergo 5:45-68

Mueller M-R, Instone S (2008) Beyond the informed consent process: continuing consent in human research. Ciência and Saúde Coletiva 13:381-389

Sachs B (2021) Contractarianism, role obligations, and political morality. Routledge, New York

Saunders B (2012)Opt-out organ donation without presumptions. J Med Ethics 38:69-72

Schaefer GO, Wertheimer A (2010) The right to withdraw from research. Kennedy Inst Ethics J 20:329-352

Upton H (2012) Presumed consent and organ donation. Clinical Ethics 7:142-146

Wendler D, Rackoff J (2002) Consent for continuing research participation: what is it and when should it be used? IRB: Ethics Human Res 24(3):1-6

Westen P (2016) The logic of consent: the diversity and deceptiveness of consent as a defense to criminal conduct. Routledge, Abingdon

Wilkinson M (2012)Opt-out organ procurement and tacit consent. J Med Ethics 38:74-75

Publisher's Note Springer Nature remains neutral with regard to jurisdictional claims in published maps and institutional affiliations. 